\title{
Análise da estrutura produtiva de pequenos agricultores: evidência empírica e implicações para políticas públicas na Zona Bragantina
}

Arisbe Mendoza Escalante - Dra . em Economia Agrícola pelo Centro de Pesquisa para o Desenvolvimento (ZEF), Universidade de Bonn, Alemanha

Resumo

O artigo apresenta uma análise acerca do uso da terra na Zona Bragantina (estado do Pará), porção oriental da região amazônica. Indica que o sistema de produção predominante na região está baseado no processo de derruba-e-queima para o preparo da terra. Apesar desta predominância, foram desenvolvidas práticas agrícolas sem o uso do fogo (a combinação de tecnologias mulch e melhoramento de técnicas). O artigo analisa as implicações relacionadas à adoção destas práticas, anunciadas como tecnologias agrícolas promissoras e que poderiam contribuir com a conservação da qualidade do solo e a vegetação secundária.

\begin{abstract}
The article presents an analyses over the land use in the Bragantina Zone (Pará State), oriental portion of the Amazon Region. It indicates that the production system predominant in the region is based on the slash-and-burn process in order to dispose the land. Despite of this predominance agriculture practice without burning (a combination of mulch technologies and better practices). The article analyses the implications related to the adoption of such practices announced as best agricultural technologies and could contributed with the soil quality conservation and the secondary vegetation.
\end{abstract}

Palavras-chave

Derruba-e-queima; vegetação secundária; práticas agrícolas sem fogo e Amazônia.

\section{Keywords}

Slash-and-burn; secondary vegetation; firefree agricultural practices the amazonia. 


\section{INTRODUÇÃO}

Grande parte da agricultura praticada na Amazônia Oriental um meio de subsistência para aproximadamente 400.000 pequenos agricultores (BRASIL, 2000) - é baseada no processo tradicional de derruba-e-queima da vegetação secundária em pousio (capoeira). Desde 1987, as preocupações globais com o desmatamento tropical e o "efeito estufa" levaram pesquisadores a investigar as práticas de uso da terra, com um foco particular na agricultura familiar (SMITH et al., 1996; TONIOLO; UHL, 1995).

Segundo Scatena et al. (1996), grande parte das pesquisas sobre dinâmica do uso da terra na Amazônia examinou as políticas de desenvolvimento, os grupos indígenas, os colonos e os fazendeiros. As discussões focalizaram as políticas e os grupos de desenvolvimento, como colonos e fazendeiros, que tiveram um forte impacto nas mudanças nas práticas tradicionais do uso da terra na Amazônia, mas negligenciaram as práticas agrícolas dos pequenos agricultores. Alguns pesquisadores acreditam que esse descuido foi sério, pois 80\% da produção agrícola total na Amazônia Oriental vêm dos pequenos agricultores, que dependem dos recursos naturais disponíveis e têm uma forte carência econômica (SERRÃO; HOMMA, 1993). Vosti, Witcover e Carpentier (2002, p. 6) observam que, "a produtividade e a pobreza entre pequenos agricultores são de importância particular na Amazônia porque a agricultura familiar tem uma presença importante em termos demográficos e econômicos".

Embora os pequenos agricultores tenham recebido menos atenção do que outros grupos, as dinâmicas da agricultura familiar na Zona Bragantina (Estado de Pará) na Amazônia Oriental foram investigadas por diversos pesquisadores (COSTA, 1992; FEARNSIDE, 1994; HURTIENNE, 2002; KITAMURA, 1982; SERRÃO; HOMMA, 1993). Ao contrário das outras partes da Amazônia, a Zona Bragantina possui uma longa história de campesinato agrícola, iniciada no começo do século XVIII. O uso da terra na região passou por diversas fases. A Zona Bragantina foi a primeira área de estabelecimento extensivo e de planejamento da Amazônia (BAAR et al., 2004). A ocupação da Zona Bragantina deu origem a um vasto processo de desmatamento , e hoje a região apresenta uma paisagem agrícola caracterizada por capoeiras de diferentes idades e por históricos de uso prévio (BURGER, 1991; DENICH, 1991; SOMMER; DENICH; VLECK, 2000).

A longa história do uso da terra por grupos não indígenas torna a Zona Bragantina interessante particularmente para muitos pesquisadores,

\footnotetext{
Até 1995, grande parte das áreas de floresta, com exceção dos igapós e dos terrenos inacessíveis, foi convertida em terra agrícola ou capoeira (SOUSA FILHO, 2003 apud HEDDEN-DUNKHORST et al., 2003).
} 
porque a maioria das pesquisas sobre práticas do uso da terra na Amazônia focalizou as fronteiras agrícolas menos estabelecidas. Além disso, a experiência da Zona Bragantina é um bom indicador do que pode acontecer em outras áreas da Amazônia, pois as fronteiras agrícolas mais recentes tornam-se cada vez mais povoadas. Por exemplo, Falesi, Baena e Dutra (1980), Rocha (1993) e Smith et al. (1995) citam a Zona Bragantina para advertir dos perigos ambientais do desenvolvimento agrícola na Amazônia e explicar como os problemas correspondentes poderão ser tratados no futuro. Esses pesquisadores acreditam que, embora as restrições ecológicas contribuam para o enfraquecimento da produção agrícola, os problemas socioeconômicos são mais importantes. Esses problemas incluem falhas do governo para fornecer a sustentação adequada, mercados desfavoráveis e habilidades administrativas impróprias dos colonos. Cada um afeta significativamente o desenvolvimento da agricultura familiar.

O sistema de produção agrícola mais comum usado pelos pequenos agricultores é o sistema de pousio. Isso inclui a derruba-e-queima de uma vegetação secundária em pousio (capoeira). O processo de derrubae-queima é seguido por um ciclo de cultivo, que inclui as culturas do milho, do feijão e da mandioca. Entretanto, nas últimas três décadas, muitos pequenos agricultores começaram a encurtar os períodos do pousio em conseqüência do aumento da densidade da população e dos incentivos do mercado para a intensificação do uso da terra. A longo prazo, essa situação afeta a fertilidade do solo e a capacidade da regeneração da capoeira, o que, por sua vez, diminui a produtividade agrícola (DENICH, 1989; HÖLSCHER et al., 1997). Além disso, o uso do fogo na preparação da terra traz custos (externos) adicionais, como problemas de saúde, emissões de gases de estufa e danos materiais provocados por fogos acidentais.

Pesquisas realizadas na região investigaram a viabilidade técnica e a produtividade de práticas agrícolas sem fogo (a combinação de tecnologias de mulch e de técnicas de melhoramento da capoeira) como alternativas para a preparação da terra. Entretanto, para que tais tecnologias sejam sustentáveis, é necessário promover o desenvolvimento econômico, reduzir a pobreza e a pressão sobre os recursos naturais. O desafio complexo das políticas públicas está relacionado à forma de estruturar as opções da tecnologia (à disposição particularmente dos pequenos agricultores) e as regras do mercado para fornecer incentivos que melhorem as potencialidades e a produtividade da agricultura familiar. Vencer esse desafio na produção agrícola familiar requer informações detalhadas sobre os estabelecimentos e uma avaliação das respostas do pequeno agricultor aos fatores do preço e a outros fatores fixos, como terra, idade da capoeira, aspetos físico-químicos do solo e trabalho da família com tecnologias alternativas na produção agrícola. 


\section{MUDANÇAS NAS POLÍTICAS AGRÍCOLAS DA ZONA BRAGANTINA}

Nas últimas quatro décadas, a agricultura familiar na Zona Bragantina adaptou-se constantemente às mudanças demográficas, sociais, políticas, econômicas e ambientais. O impacto dessas mudanças foi ampliado pela pobreza dos pequenos agricultores da região (FLOHRSCHUETZ; KITAMURA, 1991). Na última década, tal como em outras partes do Brasil, na Zona Bragantina houve projetos voltados para a redução da pobreza e a inclusão social, baseados nos indicadores sociais (VERNER, 2004). Entretanto, a pobreza no Estado do Pará é ainda grave e profunda. O Pará é um dos Estados mais pobres do Brasil. A pobreza é maior em áreas rurais. Reduzir a pobreza é um dos principais desafios para o governo na região.

A necessidade de um equilíbrio entre os objetivos de desenvolvimento econômico e os objetivos ambientais foi reconhecida pelo governo, mas ainda não assumida inteiramente. Esses problemas essencialmente estruturais são amplificados pela rigidez e pelas restrições institucionais das políticas públicas. Além disso, o governo tomou medidas na reforma que afetam a estrutura e a produtividade dos pequenos agricultores. A política agrícola (setor específico) direta mais importante foi o Programa Nacional de Fortalecimento da Agricultura Familiar (PRONAF), que resulta do programa de reforma agrária implementado na segunda metade de 1990 (HELFAND, 2003; HURTIENNE, 2002). Esse processo foi fortalecido por outra política financeira para o desenvolvimento regional da Amazônia, chamado FNO-Especial ${ }^{2}$, um programa de crédito do Ministério de Integração Nacional, lançado em 1993, dirigido especificamente aos pequenos agricultores da região.

Entretanto, os esforços do governo foram concentrados principalmente nos agricultores capitalizados que trabalhavam com cash crops (CORREA; ORTEGA, 2003; COSTA, 2000), o que resultou em um fluxo desigual dos benefícios destinados a melhorar o bem-estar dos pequenos agricultores. Não obstante, melhorias significativas na produtividade da agricultura familiar e, conseqüentemente, no bemestar econômico dos pequenos agricultores são em grande parte fruto das políticas para o desenvolvimento rural e agrícola (HURTIENNE, 2002). Mas ainda abundam ambigüidades sobre o papel e o impacto preciso do PRONAF e do FNO-Especial em aspectos como o equilíbrio entre benefícios sociais e custos sociais e ambientais.

\footnotetext{
${ }^{2}$ A Constituição de 1988 estabeleceu que 3\% dos fundos do imposto de renda arrecadado pelo governo federal iriam para os Fundos Constitucionais destinados a diminuir as brechas do desenvolvimento regional. O Fundo Constitucional de Financiamento do Norte (FNO) recebe $0,6 \%$ do total desses fundos. Para 2002/2003, os recursos do ano fiscal alocados ao crédito FNO-Especial atingiram aproximadamente 28,5 milhões de dólares (BASA, 2004).
} 
Um dos maiores desafios para o governo é tentar alcançar os objetivos de conservação ambiental sem afetar o processo essencial do desenvolvimento da região. Nesse sentido, muitas mudanças estão ocorrendo, como a implementação de uma política que visa estabelecer um programa de crédito para pequenos agricultores e criar incentivos para a adoção de práticas agrícolas sustentáveis. O PROAMBIENTE é um programa alternativo de crédito que foi implementado em 2003 pela Secretaria de Desenvolvimento Sustentável do Ministério do Meio Ambiente dentro do plano governamental (Plano PluriAnual 2004/2007) (BRASIL, 2003). Esse programa visa implantar um conjunto de serviços ambientais a fim de financiar os pequenos agricultores que praticam a agricultura sustentável.

Quando o sucesso da política depende da resposta dos pequenos agricultores aos novos incentivos, a análise das características e das opções tecnológicas na região tem recebido pouca atenção empírica na literatura (COSTA, 2000). Além disso, os pequenos agricultores são cada vez mais pressionados a buscar práticas agrícolas sem fogo para a preparação da terra devido às leis e à fiscalização de instituições nacionais e internacionais que proíbem o uso do fogo (DENICH et al., 2004). Apesar de tal pressão, os pequenos agricultores demonstraram boa vontade para adotar tais tecnologias. Durante uma ação coletiva que ocorreu no Estado do Pará entre 1990 e 1995, os pequenos agricultores revelaram que não estavam, de fato, relutantes em adotar inovações tecnológicas; reconheceram que têm desempenhado um papel importante na adoção de novas técnicas de produção . Explica Ludewigs (2002, p. 15):

muitas associações de pequenos agricultores são formadas por agricultores que têm consciência dos efeitos a longo prazo da agricultura sustentável e estão assim abertos às práticas sustentáveis, como evitar o uso de fogo e usar matéria orgânica do solo com mulching e sistemas agroflorestais.

O interesse das agências nacionais e internacionais no desenvolvimento de práticas agrícolas sem fogo surgiu durante a última década. Essas tecnologias são vistas como promissoras no fomento da produção agrícola e podem contribuir para a conservação dos recursos naturais e a sustentabilidade da agricultura familiar. Entretanto, a obtenção dos benefícios potenciais das práticas agrícolas sem fogo

\footnotetext{
3 Alguns exemplos de análises da escolha do uso da terra, comparando os lucros relativos em sistemas alternativos, são: Almeida e Uhl (1995), Arima e Uhl (1997) e Toniolo e Uhl (1995).

${ }^{4}$ Costa (2000) e Tura (2000) fornecem detalhes sobre os protestos organizados, principalmente as ações coletivas de associações de agricultores e organizações não-governamentais (ONG).
} 
depende da difusão das tecnologias e de sua adoção pela maioria dos usuários potenciais. Além disso, no cenário atual das políticas públicas voltadas para o desenvolvimento, constata-se que são oferecidos aos pequenos agricultores os mecanismos apropriados e ganhos sociais potenciais para que mudem suas práticas agrícolas, evitando o uso do fogo para preparar a terra e reduzindo o desmatamento. Espera-se compensar o lucro ao qual os pequenos agricultores renunciaram, caso as práticas agrícolas sem fogo não sejam lucrativas ${ }^{5}$. Ainda, apesar do interesse considerável por tais tecnologias e da existência de diversos estudos que comprovam a praticabilidade técnica e a produtividade das práticas sem fogo, são poucas as avaliações econômicas que examinam o impacto dessas tecnologias no bem-estar do pequeno agricultor. Além disso, a participação do pequeno agricultor, como principal contribuinte da economia da região, aumentou significativamente nas últimas décadas. Apesar disso, o bem-estar dos pequenos agricultores não aumentou tão rapidamente quanto aumentou o bem-estar dos que não são agricultores (VERNER, 2004). Por essa razão, a avaliação da estrutura da produção agrícola e o bem-estar dos pequenos agricultores transformam-se em questões importantes que têm de ser analisadas.

É certo que faltam dados sobre os estabelecimentos, faltam estudos microeconômicos sobre a oferta e a demanda na região. As decisões tomadas pelos pequenos agricultores - relativas à alocação de recursos são guiadas na maioria das vezes pelas mudanças relativas nos preços. Em tal caso, a fim de avaliar o impacto das políticas agrícolas no nível dos estabelecimentos, é necessário determinar uma medida da resposta dos pequenos agricultores às mudanças dos preços. Outros fatores-chave, como diferenças em zonas agroecológicas, infra-estrutura e tecnologia, devem também ser considerados para determinar a resposta dos pequenos agricultores às mudanças nas políticas agrícolas. Muitas perguntas permanecem sem resposta. Ignora-se a importância quantitativa dos vários fatores da produção agrícola que provavelmente afetam as mudanças na renda do pequeno agricultor, o impacto de práticas sem fogo no bem-estar do pequeno agricultor e a proporção de agricultores que se beneficiará delas, assim como os fatores dos estabelecimentos e as características principais que levam à adoção dessas tecnologias.

\section{BREVE DESCRIÇÃO DA ZONA BRAGANTINA}

A região do estudo fica situada no Nordeste Paraense, a leste de Belém, capital do Estado do Pará, o segundo maior do Brasil. A área do Estado é dividida em 143 municípios, distribuídos em 6 mesorregiões

\footnotetext{
${ }^{5}$ Sobre esse debate, ver Vosti, Witcover e Carpentier (2002).
} 
e em 21 microrregiões. Quatorze municípios dão forma à microrregião Bragantina, com uma área total de aproximadamente 11.609 km . A microrregião Bragantina compreende menos de 1\% da área total do Estado do Pará, mas contém aproximadamente 5 a $6 \%$ de sua população total (SOMMER, 2000). A região é uma das zonas agrícolas mais importantes do Nordeste do Pará.

A região do estudo atual não corresponde inteiramente à microrregião Bragantina, pois inclui municípios e comunidades adicionais que cobrem um ambiente similar na área chamada Zona Bragantina. Além da microrregião Bragantina, a região estudada inclui os arredores do centro urbano de Belém e partes da microrregião do Salgado (a noroeste da microrregião Bragantina), com uma área de aproximadamente $20.000 \mathrm{~km}^{2}$ (SOMMER, 2000). Essa área corresponde à região total do estudo.

Em um processo detahado de amostragem ${ }^{6}$, a população foi inicialmente dividida em subgrupos (estratos) e logo feita uma seleção de (percentagem) da população por meio de um processo formal aleatório. Foram escolhidos três (de um total de 16) municípios rurais, 22 comunidades e 271 estabelecimentos para uma análise detalhada. Os municípios selecionados foram: Castanhal, Igarapé-Açu e Bragança, que têm, respectivamente, $1029 \mathrm{~km}^{2}, 786 \mathrm{~km}^{2}$ e $2090 \mathrm{~km}$.

O clima na Zona Bragantina é úmido, com um período de seca de setembro a dezembro. A precipitação anual média está entre 17002700 milímetros, com variações, havendo uma época seca de pelo menos um mês. De acordo com Falesi, Baena e Dutra (1967), a extensão do período da época seca varia ao longo da Zona Bragantina, de modo que as partes ocidentais experimentam épocas secas mais curtas do que as partes orientais. As quantidades pluviométricas totais não variam significativamente. Há variações mensais na escala de temperatura média entre $25.5^{\circ} \mathrm{C}$ e $26.8^{\circ} \mathrm{C}$, e a umidade relativa está entre $80 \%$ e 89\% (KATO, M., 1998; KATO, O., 1998). A vegetação natural da Zona Bragantina é floresta da Amazônia. Entretanto, hoje a maioria dos tipos da vegetação da região concentra-se somente em algumas áreas pequenas, devido ao desmatamento provocado pelo estabelecimento humano (KATO, M., 1998; SOMMER, 2000). Predomina atualmente a vegetação secundária, que cobre mais de 50\% da área (IBGE, 1998).

Em áreas densamente povoadas, como a Zona Bragantina, a vegetação secundária (capoeira) em pousio desempenha um papel-chave na manutenção da produtividade da terra e dos solos (DENICH, 2001). A capoeira possui também outras funções importantes, contribuindo para a regeneração da floresta, a dissipação do carbono e a conservação

${ }^{6}$ Ver Börner et al. (2002) para detalhes da amostragem. 
da biodiversidade. Um estudo feito em 92 áreas de capoeira (de 1 a 10 anos de idade) por Baar et al. (2004) identificou 673 espécies de plantas, que incluem 316 espécies de árvores. Além disso, as capoeiras oferecem também uma variedade de produtos econômicos úteis, como a lenha, materiais de construção, madeira, mel e frutas, etc, que, no entanto, não são pesquisados freqüentemente (SOMMER et al., 2000; CORLETT, 1995) ${ }^{7}$. A análise do survey mostra que atualmente a idade média da capoeira é de 10 anos; as capoeiras de 0 a 10 anos correspondem a quase $60 \%$ da capoeira dos pequenos agricultores (Tabela 1).

Tabela 1: Características da capoeira na Zona Bragantina, por município.

\begin{tabular}{|c|c|c|c|c|}
\hline & Castanhal & Igarapé-Açu & Bragança & Todos \\
\hline $\begin{array}{l}\text { \% capoeira (do total do } \\
\text { estabelecimento em ha) }\end{array}$ & 55 & 64 & 58 & 58 \\
\hline $\begin{array}{l}\text { \% capoeira } 0-10 \text { anos (do total } \\
\text { do estabelecimento) }\end{array}$ & 31 & 44 & 31 & 34 \\
\hline $\begin{array}{l}\% \text { capoeira }>11 \text { anos (do total } \\
\text { do estabelecimento) }\end{array}$ & 24 & 19 & 27 & 24 \\
\hline Idade média da capoeira (anos) & 11 & 10 & 8 & 10 \\
\hline $\begin{array}{l}\text { Valor médio dos produtos } \\
\text { da capoeira ( } \mathrm{R} \$ \text { ano- } 1)\end{array}$ & 109 & 33 & 104 & 84 \\
\hline
\end{tabular}

Fonte: SHIFT ENV 44. Bragantina Baseline Survey (2002).

A paisagem da Bragantina é na maior parte plana (DENICH et al., 2004; SOMMER, 2000). De acordo com o Projeto RADAMBRASIL (1973), o solo predominante na região é latossolo amarelo (Oxisol). A utilização intensiva dos solos provocou a remoção da argila nas camadas mais profundas, o que resulta na degradação dos horizontes superiores (VIELHAUER et al., 1998). De acordo com os resultados obtidos por Sommer (2000), os solos são caracterizados pelo baixo carbono (C), pelo baixo nitrogênio $(\mathrm{N})$ e pelas baixas concentrações de fósforo $(\mathrm{P})$ disponíveis para a planta, pela capacidade baixa de troca de cátions no solo (CEC) e pela saturação elevada do alumínio no subsolo. A textura é arenosa nas camadas mais profundas.

A Tabela 2 fornece alguns dados sobre as diferenças regionais entre os municípios estudados. Os dados são resultado de uma análise de parâmetros importantes do solo das 476 parcelas selecionadas. Diferenças significativas nas médias puderam ser observadas para o pH e o peso seco da biomassa, com as médias mais elevadas

\footnotetext{
${ }^{7}$ A Tabela 1 mostra que o valor médio de produtos da capoeira atinge $\mathrm{R} \$ 84,00 \mathrm{ano}^{-1}$ na área do estudo. Isso inclui variações grandes entre os municípios do estudo, mas também entre os estabelecimentos.

${ }^{8}$ Um método do bio-test foi empregado para estimar o peso seco acima da biomassa, usada para aproximar a fertilidade de solo. Para uma descrição detalhada, consultar Mendoza Escalante (2005).
} 
alcançadas em Bragança. Os testes da homogeneidade entre municípios para avaliar os parâmetros do solo revelaram que Castanhal e IgarapéAçu têm níveis mais ou menos similares, enquanto os de Bragança são diferentes na maioria. Isso se deve à ausência de diferenças significativas entre Castanhal e Igarapé-Açu em relação ao peso seco da biomassa e ao fósforo disponível. A respeito dos níveis do $\mathrm{pH}$, Alburquerque e Cardoso (1980) relataram que o grau de acidez requerido para a mandioca, o principal alimento produzido na região, deve estar entre pH 6.0 e 6.5, de acordo com Ximenes (2001). Contudo os dados da análise de solo mostram que o grau de acidez encontrado na Zona Bragantina está entre pH 4.6 e 4.9 (ver Tabela 2).

Tabela 2: Comparação de parâmetros do solo, por município.

\begin{tabular}{l|c|c|c}
\hline \multirow{2}{*}{ Variável } & \multicolumn{3}{|c}{ Diferenca média absoluta entre municípios } \\
\cline { 2 - 4 } & $\begin{array}{c}\text { Castanhal vs. } \\
\text { Igarapé-Açu e } \\
\text { Bragança }\end{array}$ & $\begin{array}{c}\text { Igarapé-Açu vs. } \\
\text { Castanhal e } \\
\text { Bragança }\end{array}$ & $\begin{array}{c}\text { Bragança vs. } \\
\text { Igarapé-Açu e } \\
\text { Castanhal }\end{array}$ \\
\hline PH & $4.60^{*}$ & $4.92^{*}$ & $4.91^{* *}$ \\
Peso seco biomassa (q) & 0.57 & $0.51^{* *}$ & $0.66^{* *}$ \\
Fósforo disponível (mq/100 q) & 0.55 & 0.56 & 0.64 \\
\hline
\end{tabular}

* Significativo ao nível 0.10.

** Significativo ao nível 0.05.

Fonte: SHIFT ENV 44. Bragantina Baseline Survey (2002).

A Zona Bragantina tem aproximadamente meio milhão de habitantes (ver Tabela 3), 65\% dos quais moram em áreas urbanas. O crescimento da população no período de 1991 a 2000 realizou-se em 1.8\% da região, estando abaixo da média da expansão da população para o Estado do Pará (VERNER, 2004). A região está tornando-se altamente urbanizada, mas a urbanização difere significativamente ao longo da Zona Bragantina. Em 2000, 90\% da população do município de Castanhal moravam em áreas urbanas, a maioria na capital do município, que também se chama Castanhal. Nos outros dois municípios estudados, a população urbana equivale a 60\%. Esses municípios têm áreas urbanas muito menores e proporções maiores de pequenos agricultores em relação às fazendas de médio ou grande porte, que aumentam o número das famílias por área. Isso também se reflete na proporção da população que trabalha na agricultura: 18\% em Castanhal, 21\% em Igarapé-Açu e 32\% em Bragança.

A densidade da população é modesta em Igarapé-Açu e em Bragança (38 e 36 habitantes por km , respectivamente), muito maior em Castanhal (114 habitantes por km² ). A alfabetização não é uniforme nos municípios. Assim, a taxa de alfabetização da população inteira (acima de nove anos) é de aproximadamente 80\% na área do município de Castanhal, mas de 
88\% na capital, Castanhal. Não obstante, Verner (2004, p. 20) relatou que, no Estado de Pará, no período de 1991 a 2000, a taxa de alfabetização para habitantes acima de 15 anos passou de 8.9\% (1991) para 17\% (2000). O autor enfatiza, entretanto, que a redução das taxas de analfabetismo é dificultada pelo fato de que muitos analfabetos são adultos, é mais difícil fornecer acesso ao ensino aos adultos do que às crianças.

Tabela 3: Indicadores demográficos para a Zona Bragantina.

\begin{tabular}{l|r|r|r|r}
\hline & \multicolumn{1}{|c|}{$\begin{array}{c}\text { Zona } \\
\text { Bragantina }\end{array}$} & Castanhal & $\begin{array}{c}\text { Igarapé- } \\
\text { AÁu }\end{array}$ & Bragança \\
\hline $\begin{array}{l}\text { População total } \\
\text { Densidade de populaÁ, o }\end{array}$ & 463680 & 134496 & 32400 & 93779 \\
(habitantes/km²) & $-\mathrm{b}^{2}$ & 114 & 38 & 36 \\
Taxa de alfabetização (? 10 anos) & 80,7 & 88,0 & 79,6 & 79,9 \\
\% população urbana & 65 & 90 & 60 & 60 \\
\% população rural & 35 & 10 & 40 & 40 \\
\% população trabalhando na & & & & \\
agricultura & 16 & 18 & 21 & 32 \\
Área do estabelecimento (ha) & 405146 & 60904 & 46655 & 134617 \\
\hline
\end{tabular}

${ }^{a}$ Definida aqui como a região do estudo, compreende a microrregião Bragantina e Castanhal.

${ }^{\mathrm{b}}$ Dados não disponíveis.

Fonte: IBGE (1998).

\section{ENFOQUE METODOLÓGICO}

Tanto a avaliação econômica da estrutura da produção agrícola, quanto o bem-estar dos pequenos agricultores são os alvos deste estudo. O objetivo é suscitar uma discussão sobre as respostas do pequeno agricultor a determinados fatores, como os preços, e também propor a exploração dos resultados dessa discussão na elaboração de políticas públicas para a Zona Bragantina.

Considerando os dois focos distintos do estudo atual, a pesquisa foi organizada em duas partes: a) a produção agrícola dos pequenos agricultores e b) as práticas agrícolas sem fogo. A primeira parte, a produção agrícola dos pequenos agricultores, trata de uma estrutura que pode predizer os impactos de políticas do governo na produção agrícola na Zona Bragantina. A segunda parte, as práticas sem fogo, concentra-se nos impactos no estabelecimento das tecnologias sem fogo, examinando a possibilidade de sua adoção.

\subsection{Produção agrícola dos pequenos agricultores}

Tenta-se, na primeira parte, responder às seguintes perguntas:

a) Quais as principais características das tecnologias da produção na agricultura da região? 
b) Qual a importância quantitativa dos vários fatores da produção que podem provocar mudanças na renda dos pequenos agricultores?

A fim de responder a essas perguntas, funções da demanda e oferta são estimadas usando-se um modelo dual de funções lucro restritas, baseado na teoria da produção (HOTELLING, 1932; SAMUELSON, 1953; SHEPARD, 1970). O objetivo geral é fornecer algumas estimativas empíricas da resposta a curto prazo dos pequenos agricultores às políticas do governo que afetam os preços da oferta e demanda. A aproximação econométrica que foi usada para estimar as funções da demanda e oferta é o procedimento Seemingly Unrelated Regression, em que as condições da homogeneidade e da simetria são impostas.

\subsection{As práticas agrícolas sem fogo}

Uma vez conhecidas os determinadores do lucro do estabelecimento e o retorno dos fatores para a agricultura da região, a etapa seguinte consiste em examinar os benefícios reais das práticas agrícolas sem fogo (a combinação de tecnologias de mulching ${ }^{10}$ ). Além disso, é feita uma tentativa de medir a adoção potencial das tecnologias. Para isso, na segunda parte do estudo, tenta-se responder às seguintes perguntas:

a) Qual a contribuição da tecnologia de mulching para o bemestar do pequeno agricultor? Se não existir lucro, quais as implicações para as políticas relacionadas à agenda de pesquisa na agricultura?

b) O que leva os agricultores a adotar as práticas agrícolas sem fogo? Quais as áreas da política que podem afetar a decisão dos agricultores e o que se deve fazer para mitigar as dificuldades?

Para responder ao primeiro grupo de perguntas da pesquisa, usase a teoria descrita no item anterior. O objetivo é estimar os impactos do uso das práticas agrícolas sem fogo nos lucros do agricultor. Para conseguir dados consistentes com o comportamento de maximização do lucro, as funções da demanda e oferta são derivadas empiricamente de uma função do lucro e estimadas em um sistema similar àquele do modelo discutido na primeira parte. Finalmente, para responder ao segundo grupo de pergunta, usam-se métodos de valoração contingente. As determinantes do potencial de adoção das práticas sem fogo são identificadas usando-se um modelo de escolha dupla (double dichotomous choice) (HUBELL et al., 2000; QAIM; JANVRY, 2003). Assim, uma aproximação de escolha dupla é empregada para determinar a disponibilidade para adotar as tecnologias. Tanto os modelos contínuos, quanto o modelo duplo simples não podem ser usados para analisar a resposta dos agricultores. Além disso, o segundo grupo de respostas

\footnotetext{
${ }_{10}^{9}$ Para detalhes e explanação, ver Mendoza Escalante (2005).

O estudo analisou somente uma das práticas agrícolas sem fogo (tecnología de trituração mulching).
} 
está ligado à informação fornecida na primeira resposta. Avaliar as duas respostas independentemente ou juntar as respostas para chegar a uma única equação pode levar a resultados inválidos. Assim, o método econométrico usado para tratar as duas respostas relacionadas é o modelo bivariate probit.

A hipótese principal que está sendo testada neste estudo é que "o uso da tecnologia pelos pequenos agricultores será melhorado dandose atenção mais explícita ao mercado subjacente e aos outros fatores (de entrada e saída) que determinam o lucro econômico".

\section{RESUMO DO ENFOQUE EMPÍRICO}

Os dados usados na análise resultam de dois surveys realizados na Zona Bragantina no âmbito do projeto SHIFT ENV $44^{11}$. Para a análise da produção agrícola dos pequenos agricultores, o estudo abrangeu um total de 271 estabelecimentos em 22 comunidades, assim distribuídos: 91 estabelecimentos de sete comunidades do município de Igarapé-Açu, 90 estabelecimentos de três comunidades do município de Castanhal e 91 estabelecimentos de doze comunidades do município de Bragança. O survey foi realizado no período de outubro a dezembro de 2002, cobrindo a colheita de 2001/2002. A amostragem foi feita em dois estágios, envolvendo subgrupos (estratos) no primeiro e a seleção aleatória no segundo estágio. O questionário consistiu principalmente em perguntas relacionadas às características dos sistemas agrícolas e dos estabelecimentos. Além disso, para cada um dos 271 estabelecimentos, foram coletadas informações específicas de duas parcelas selecionadas de forma aleatória, em que foram plantadas culturas anuais. Esse survey foi realizado no período de dezembro de 2002 a fevereiro de 2003. No total, 441 parcelas foram investigadas. Entretanto, a amostragem do solo e a análise subseqüente não poderiam ser realizadas para todas as parcelas; por isso, o número das observações usadas na função de lucro para a análise dos padrões da produção agrícola foi reduzido a 383.

O segundo survey foi realizado em Barcarena e em Igarapé-Açu, servindo para a análise de práticas agrícolas sem fogo. Um total de 57 estabelecimentos em 10 comunidades (41 estabelecimentos de oito comunidades do município de Igarapé-Açu e 16 estabelecimentos de duas comunidades do município de Barcarena) foi incluído no estudo. O survey foi realizado de maio a junho de 2003, cobrindo a colheita de

\footnotetext{
${ }^{11}$ O Projeto SHIFT ENV 44 - Smallholders in the Amazon: Interactions between Ecosystem and Social System in the Use and Protection of Tropical Rain Forests -, financiado pelo Ministério alemão da Educação, Ciência, Pesquisa e Tecnologia (BMBF), faz parte do Programa Studies on Human Impact on Forests and Floodplains in the Tropics.
} 
2001/2002. Os agricultores foram selecionados propositadamente para incluir 90\% dos que já estavam experimentando as tecnologias sem fogo e continuariam adotando a tecnologia durante o período do estudo. O questionário incluiu as perguntas relacionadas às características do sistema agrícola e do estabelecimento, entre outras perguntas. Além disso, para cada um dos 57 estabelecimentos, foi coletada informação específica de duas parcelas (isto é, uma parcela com a tecnologia sem fogo e outra parcela com derruba-e-queima) para finalidades de comparação. No total, 101 parcelas forem investigadas.

\section{RESULTADOS}

\subsection{Produção agrícola dos pequenos agricultores}

A produção agrícola dos pequenos agricultores depende das condições ambientais da produção, que são, por sua vez, determinadas em geral por fatores exógenos. Mesmo que as condições ambientais (isto é, os solos) na Zona Bragantina sejam classificadas como homogêneas, as variações do clima, sobretudo das chuvas, refletem as diferenças intra-regionais. As condições físicas e climáticas, assim como o tipo de tecnologia usado na preparação da terra, podem significativamente influenciar o resultado dos esforços para melhorar a renda dos pequenos agricultores. No que diz respeito à demografia, a população da Zona Bragantina aumentou 32\% em quinze anos (de 1980 a 1995). Isso implica um aumento da demanda de alimento, que se reflete no aumento das terras cultivadas e na diminuição das áreas da capoeira. Ainda, a idade média das áreas de capoeira é de 10 anos.

Um problema adicional enfrentado pelos pequenos agricultores na região é a pobreza estrutural. A Zona Bragantina é a quinta microrregião mais pobre do Estado do Pará em termos de renda per capita anual. De acordo com a análise baseada nos dados do survey, a média anual da renda per capita nos municípios do estudo em 2002 foi de R\$ 1558 ou \$ 577 USD. A renda média de 25\% dos estabelecimentos mais pobres da amostra foi de aproximadamente \$ 90 USD, equivalente a 22 vezes menos do que a renda de $25 \%$ dos estabelecimentos mais ricos da amostra, o que indica uma distribuição de renda muito desigual. Certamente, o coeficiente do Gini, calculado em 0.64, indica uma desigualdade mais elevada do que aquela estimada por Verner (2004) para o Estado de Pará, ao redor 0.60. Em geral, o produto das atividades agrícolas é a fonte mais importante da renda dos estabelecimentos aproximadamente $70 \%$ da renda total. Entretanto, a análise das fontes de renda revela que a maioria dos pequenos agricultores pobres não depende da agricultura somente, depende também dos salários de fora das atividades agrícolas, que respondem por 30\% de sua renda, mas 
correspondem a somente $10 \%$ da renda das famílias mais ricas. As pensões parecem ser uma fonte de renda importante para os estabelecimentos pobres e "semipobres". Os dados do surveyrevelaram que aproximadamente 50\% dos estabelecimentos com nível médio recebem mais pensões - uma média de $20 \%$ de sua renda total. Os $25 \%$ mais pobres recebem aproximadamente $13 \%$ de sua renda total.

Entre os pequenos agricultores, existe uma relação inversa entre a renda, o tamanho da família e o indicador da relação de dependência (dependency ratio). A relação de dependência do grupo mais pobre da amostra indica que ela é duas vezes maior do que a do grupo mais rico. Essa relação mais elevada de dependência no grupo mais pobre é resultado do número maior de crianças nas famílias, aproximadamente 40\% mais do que a média do grupo mais rico. A idade dos membros do estabelecimento afeta a renda da casa negativamente. Quanto mais novas as crianças, mais pobre é o agricultor. Adicionalmente, os membros mais velhos da família têm as rendas médias mais elevadas, o que pode ser explicado em parte pelas aposentadorias rurais. O nível educacional é baixo e está correlacionado também com a renda. A taxa de alfabetização é elevada para $25 \%$ dos estabelecimentos mais pobres da amostra, atingindo a taxa de 40\% entre os chefes de família. As gerações mais novas têm níveis de instrução mais elevados, mas esses níveis ainda estão longe do aceitável. O número médio de anos de educação para todos os membros da casa do estabelecimento maiores de 16 anos de idade é 4.5 anos, o que revela que o nível educacional ainda é baixo. A distribuição da educação é também completamente desigual, mas melhora nas gerações mais novas. O número médio de anos de educação das famílias mais pobres é inferior à metade da média das famílias mais ricas. O coeficiente de Gini por anos terminados da educação para os chefes de família é 0.32. Isso sugere que fornecer uma educação melhor aos pequenos agricultores mais pobres melhoraria seus níveis de vida. Para interpretar esses resultados, seria necessária uma análise mais profunda da causalidade renda-educação, o que extrapola os objetivos deste estudo.

Apesar da existência de programas governamentais dirigidos aos pequenos agricultores (por exemplo, PRONAF e FNO-Especial), os resultados da amostra indicam que o acesso aos serviços como a extensão agrícola e o crédito é impressionantemente limitado. O acesso ao crédito (em forma de subvenção) é baixo para todos os níveis de

${ }^{12}$ Definida pelo número dos membros da família por trabalhador. Dividiu-se o número de membros da família menores de 16 anos e o número de membros da família maiores de 65 anos pelo número de membros da família com idade para trabalhar (aqueles entre 15 e 64 anos). 
renda: de acordo com a média da amostragem, somente $23 \%$ dos pequenos agricultores tiveram acesso ao crédito. A assistência técnica alcança também uma porcentagem muito pequena dos pequenos agricultores, sendo somente realmente significativa para o grupo mais rico. Esses números sugerem que a falta de acesso à assistência técnica e ao crédito é um grave problema entre pequenos agricultores, especialmente no grupo mais pobre. Além disso, o uso de insumos, de maquinaria, de crédito e de assistência técnica é muito maior entre os agricultores mais ricos. O uso de maquinaria (em forma de mecanização para a preparação da área) e o uso de fertilizante é relativamente freqüente. Por exemplo, em média, aproximadamente $40 \%$ e $70 \%$ dos estabelecimentos mencionaram o uso de fertilizante e mecanização, respectivamente. Isso é particularmente importante para a Zona Bragantina, porque o uso da maquinaria muda os sistemas agrícolas e causa forte impacto na capoeira ${ }^{13}$. Além disso, a tecnologia do mulching utiliza uma trituradeira mecânica e precisa do uso de fertilizante a fim de suplementar as perdas de nutrientes que derivam da biomassa da vegetação em pousio (capoeira). Assim, o fato de grande parte dos pequenos agricultores empregarem mecanização e fertilizante faz crer que muitos poderão aceitar tecnologias como o mulching.

Tabela 4: Distribuição da terra, por grupos de renda total per capita.

\begin{tabular}{|c|c|c|c|c|c|}
\hline & \multicolumn{5}{|c|}{ Níveis de renda } \\
\hline & Todos & Baixo & $\begin{array}{c}\text { Médio } \\
\text { baixo }\end{array}$ & $\begin{array}{l}\text { Médio } \\
\text { alto }\end{array}$ & Alto \\
\hline Tamanho do estabelecimento (ha) & 21.2 & 17.4 & 19.6 & 15.8 & 31.9 \\
\hline \multicolumn{6}{|l|}{ Total área cultivada } \\
\hline Culturas anuais (ha) & 3.3 & 2.2 & 2.6 & 2.9 & 5.1 \\
\hline Culturas permanentes (ha) & 1.5 & 0.8 & 0.7 & 0.7 & 1.8 \\
\hline Pastagens (ha) & 2.1 & 1.6 & 1.1 & 1.0 & 4.7 \\
\hline Capoeira (ha) & 12.3 & 10.2 & 11.2 & 10.1 & 17.4 \\
\hline Terra sem uso (ha) & 2.1 & 2.6 & 3.9 & 1.1 & 2.9 \\
\hline $\begin{array}{l}\text { Proporção do valor total do estabelecimento } \\
\text { proveniente de cash crops }\end{array}$ & 30.5 & 35.2 & 20.9 & 23.7 & 42.2 \\
\hline $\begin{array}{l}\text { Proporção do valor total do estabelecimento } \\
\text { proveniente de culturas anuais }\end{array}$ & 68.1 & 63.2 & 78.3 & 76.2 & 54.4 \\
\hline $\begin{array}{l}\text { Proporção do valor total do estabelecimento } \\
\text { proveniente da pecúaria }\end{array}$ & 0.4 & 0.6 & 0.7 & 0.0 & 0.2 \\
\hline
\end{tabular}

Fonte: SHIFT ENV 44. Bragantina Baseline Survey (2002).

\footnotetext{
${ }^{13}$ A capoeira é parte integrante do sistema e essencial para a regeneração de nutrientes. Além disso, a mecanização remove as raízes da vegetação da capoeira e reduz assim sua capacidade de regeneração (DENICH, 1989).
} 
A Tabela 4 mostra que a desigualdade da distribuição da terra é relativamente elevada, mesmo considerando que os estabelecimentos maiores (fazendas) não estão incluídos na amostra. No grupo mais pobre, o tamanho médio dos estabelecimentos é 17.4 hectares, enquanto no grupo mais rico é 31.9 hectares. As culturas anuais são a fonte de renda mais importante para todos os estabelecimentos da amostra. As culturas anuais e permanentes são cultivadas como cash crops. Ainda, $25 \%$ dos estabelecimentos mais pobres dependem mais das culturas anuais, responsáveis por 65\% do valor total da produção; já em 25\% dos estabelecimentos mais ricos as culturas anuais correspondem a $50 \%$ do valor total da produção. Os problemas de liquidez dos estabelecimentos mais pobres podem explicar seu investimento relativamente mais baixo em culturas permanentes. A pecuária tem um papel menor nos estabelecimentos examinados. Por causa dessas diferenças na estrutura da produção, o impacto esperado de inovações tecnológicas na renda dos pequenos agricultores é diferenciado.

\subsection{Importância quantitativa dos vários fatores da produção que afetam a renda dos pequenos agricultores}

A função quadrática normalizada foi aplicada aos dados ${ }^{14}$ (BAPNA; BINSWANGER; QUIZON, 1984; BAUTISTA, 1986; FONTEIN et al., 1994; KHERALLAH; GOVIDAN, 1999; LAU, 1976; LÓPEZ, 2000; SHUMWAY, 1983; SHUMWAY; ALEXANDER, 1988; WALL; FISHER, 1987). As técnicas Seemingly Unrelated Regression foram empregadas (ABRAR; MORRISEY; RAYNER, 2002; AHAMMAD; ISLAM, 1999; BEYERS; HASSAN, 2000; HUFFMAN; EVENSON, 1989; KHERALLAH; GOVIDAN 1999). Do mesmo modo, as propriedades teóricas da homogeneidade e da simetria da função do lucro foram impostas no modelo, enquanto a propriedade de monotonicidade foi testada. As propriedades estruturais que não foram impostas durante a estimação foram logo testadas. Devido à falta de dados apropriados, a agregação da oferta e de um grupo homogêneo para o fertilizante foi necessária. A hipótese mantida era que os pequenos agricultores maximizam o lucro da produção de um consórcio de culturas que rende os retornos mais elevados dos recursos empregados na produção com oferta dada e preços de insumos variáveis e nível de insumos fixos. Cada estabelecimento foi tratado como uma unidade de

${ }^{14}$ Essa forma funcional foi escolhida porque permite a existência de níveis zero de utilização de fatores e/ou produções. Além disso, para essa forma funcional, a existência de convexidade local tem como conseqüência a existência de convexidade global. Adicionalmente, os coeficientes da matriz Hessiana são constantes, o que permite o simples cálculo analítico dos valores de equilíbrio a longo prazo daqueles fatores que são fixos a curto prazo (LAU, 1976). Para os detalhes da especificação econométrica, ver Mendoza Escalante (2005). 
produção que pudesse produzir uma oferta agregada usando diversos insumos. A produção foi agregada compreendida pela mandioca, pelo milho e pelo feijão. Os insumos variáveis eram fertilizante (NPK) e trabalho empregado. Os insumos fixos considerados eram terra, idade da capoeira, reação do solo $(\mathrm{pH})$ e trabalho da família (mão-de-obra familiar).

Os resultados da especificação conformaram-se com as exigências teóricas para a função do lucro (LAU, 1978). Os resultados deste estudo sugerem que os pequenos agricultores da Zona Bragantina são agentes racionais maximizadores do lucro e usam os recursos eficientemente até o ponto em que os retornos marginais são zero. Foram calculadas as elasticidades , as estimativas de elasticidades parciais da oferta de produção e as demandas de insumos relativas aos preços e aos fatores fixos (ver Tabelas 5 e 6). As elasticidades estimadas captam as ligações entre a produção, os insumos e seus preços na Zona Bragantina e fornecem conseqüentemente informações economicamente úteis. Em detalhe, essas estimativas podem ser usadas para quantificar os ajustes prováveis que ocorreriam na produção planejada em resposta às mudanças previstas nos preços dos insumos e dos produtos. Entretanto, essas estimativas devem ser usadas com cuidado por causa das suposições subjacentes do modelo.

Tabela 5: Elasticidade para a oferta de produção e demanda de insumos ${ }^{a}$.

\begin{tabular}{|c|c|c|c|}
\hline & \multicolumn{2}{|c|}{$\begin{array}{c}\text { Preço dos insumos } \\
\text { (erros-padrão entre parênteses) }\end{array}$} & Preço do produto \\
\hline $\begin{array}{l}\text { Oferta de produção ou } \\
\text { demanda do fator }\end{array}$ & Fertilizante & Salário & Preço \\
\hline Fertilizante & $-2.475(0.384)$ & $(0.002)$ & 409) \\
\hline Trabalho empregado & $0.029(0.001)$ & $-1.431(0.085)$ & $1.402(0.089)$ \\
\hline Produção agregada & $-0.124(0.031)$ & $-0.004(0.001)$ & $0.128(0.031)$ \\
\hline
\end{tabular}

a As médias e os erros-padrão das elasticidades dos estabelecimentos são calculados usando-se uma observação para cada um deles, avaliada com preços médios. Os erros-padrão são calculados com bootstrapping em uma re-amostragem de 500 dados.

Tabela 6: Elasticidade para a oferta de produção e demanda dos fatores fixos ${ }^{a}$.

\begin{tabular}{l|c|c|c|c}
\hline & \multicolumn{4}{|c}{ Fatores Fixos (erros-padrão entre parênteses) } \\
\hline $\begin{array}{l}\text { Oferta de produção ou } \\
\text { demanda do fator }\end{array}$ & Terra & $\begin{array}{c}\text { Trabalho da } \\
\text { família }\end{array}$ & $\begin{array}{c}\text { Idade da } \\
\text { capoeira }\end{array}$ & $\mathrm{pH}$ \\
\hline Fertilizante & $0.222(0.048)$ & $-0.032(0.007)$ & $-0.052(0.014)$ & $-0.041(0.008)$ \\
Trabalho empregado & $1.713(0.162)$ & $-0.000(0.000)$ & $0.014(0.001)$ & $-0.175(0.016)$ \\
\hline
\end{tabular}

a As médias e os erros-padrão das elasticidades dos estabelecimentos são calculados usando-se uma observação para cada um deles, avaliada com preços médios. Os erros-padrão são calculados com bootstrapping em uma re-amostragem de 500 dados.

\footnotetext{
${ }^{15}$ A elasticidade é uma medida do grau em que os agricultores respondem a mudanças nas condições de mercado. É também uma medida da resposta da quantidade demandada ou ofertada a mudanças em uma de suas determinantes.
} 
A elasticidade-preço da demanda de fertilizante e o trabalho empregado mede em quanto a quantidade demandada aumenta (diminui) em resposta à queda (ao aumento) do preço e dos fatores fixos; a elasticidade-preço da oferta de produção mede em quanto a quantidade ofertada aumenta (diminui) em resposta à queda (ao aumento) do preço e dos fatores fixos. Os resultados sugerem que as políticas de preço poderiam ser empregadas para estimular os pequenos agricultores a usar mais fertilizante a fim de balancear a fertilidade do solo declinante e aumentar a produção, desde que a idade da capoeira e os fertilizantes fossem considerados como fatores substitutos. Por outro lado, se houver uma redução no preço do fertilizante, sob preços constantes, é provável que ocorra um aumento na área cultivada, provocando mais pressão nos recursos naturais. Estudos na África do Sul mostraram que a elevação dos preços dos fertilizantes parece induzir um desmatamento maior (MONELA, 1996; AUNE et al., 1997; HOLDEN, 1997). O modelo sugere que os salários rurais mais elevados induzem somente um aumento pequeno na produtividade agrícola. Há, conseqüentemente, fortes razões para acreditar que as políticas que favorecem aumentos dos salários rurais e geram oportunidades de emprego fora do estabelecimento reduzem a pressão nos recursos naturais.

Os resultados sugerem também que a produção agregada dos pequenos agricultores na Zona Bragantina responde somente modestamente aos incentivos de preço, e a resposta ao preço do produto é maior do que a resposta aos preços de insumos variáveis. Quando as mudanças nos preços de insumos variáveis afetarem significativamente a demanda desses insumos, a influência dos preços de insumos na produção será insignificante, em especial para o trabalho empregado. É improvável que a aplicação de políticas dirigidas a preços de produtos tenha um efeito apreciável na produção agregada. Não se trata aqui de discutir a questão da política voltada para uma estrutura de preços sem distorções, pois pode haver efeitos nos consórcios da colheita capturada no foco da produção agregada, e se esperaria que as elasticidades do preço aumentassem à medida que a agricultura se tornasse mais comercial.

Os mecanismos de sustentação dos preços, talvez como parte do programa de extensão, podem ser necessários para incentivar o uso do fertilizante (pelo menos até que a renda média do estabelecimento aumente). Entretanto, atenção especial deve ser dada ao comportamento econômico dos pequenos agricultores em relação ao uso do fertilizante. Por exemplo, as atitudes para o risco (que induzem o subconsumo dos insumos), a falta geral do dinheiro ou do crédito (que impedem a alocação eficiente do tempo), a coexistência de várias atitudes em relação à aversão ao risco e ao acesso ao crédito combinam dificuldades analíticas 
c]om a possibilidade de substituição das demandas nessas várias categorias quando há variações nos preços. Além disso, por um lado, os preços mais elevados do fertilizante levam os pequenos agricultores a adotar sistemas de produção mais extensivos, que usem mais terra e menos fertilizante; por outro lado, os custos mais elevados, associados ao aumento do uso dos fertilizantes, tornam a agricultura menos lucrativa e podem provocar uma redução na quantidade de terra destinada às culturas (ANGELSEN; KAIMOWITZ, 1999).

Quando o preço dos produtos muda, o padrão dos consórcios das culturas e as demandas de mão-de-obra alteram-se. Além disso, nas decisões sobre a tecnologia a adotar para o preparo da área e nas ações de conservação do solo, em que se levam em conta a produtividade a longo prazo da terra e a gerência dos recursos sustentáveis, as mudanças nos padrões de uso da terra provocadas por choques externos, como o preço de mercado ou mudanças na política, afetarão também as decisões sobre a tecnologia na demanda de mão-de-obra nas atividades agrícolas. As oportunidades de emprego fora do estabelecimento, por exemplo, poderiam ter um impacto significativo nas decisões sobre a alocação da mão-de-obra na agricultura.

Quando a estimativa do modelo dual de funções lucro restritas da tecnologia da produção supõe que os pequenos agricultores maximizam os lucros, isto é, os rendimentos líquidos dos custos variáveis, os preços sombra (preços virtuais) ${ }^{16}$ são úteis para determinar o valor adicionado do estabelecimento. Esses valores duplos ajudam o pequeno agricultor, especialmente a alocar insumos fixos altamente produtivos e a usá-los apropriadamente. Outras restrições adicionais são reveladas também. Por exemplo, se o preço sombra do fertilizante for muito mais elevado para um estabelecimento particular do que o preço de mercado aparente, se seu uso real constitui uma restrição produtiva e se o agricultor não tiver o capital suficiente para comprar, então o preço do fertilizante não é realmente aplicável no estabelecimento ou os riscos de usar quantidades maiores são considerados muito grandes.

A Tabela 7 apresenta uma avaliação dos efeitos de vários fatores no lucro baseada nos coeficientes estimados para a função de produção

\footnotetext{
${ }^{16}$ A noção de preço virtual é uma extensão natural da teoria da dualidade. De acordo com essa noção, há uma ligação entre a função lucro restrita (a alguns fatores e/ou produções) de curto prazo e a função lucro não restrita de longo prazo. Preços virtuais são aqueles preços que fariam um agricultor sem restrições produtivas comportar-se com se estivesse enfrentando essas restrições. Mais concretamente, os preços sombra dos fatores e/ou produções fixas a curto prazo podem ser encarados como preços virtuais. Esses preços sombra não são mais do que os preços de longo prazo que tornariam ótimas as quantidades observadas desses fatores e/ou produções a curto prazo.
} 
quadrática normalizada. Pode-se ver como os vários preços e outros fatores afetam o preço sombra da capoeira. De acordo com as estimativas, o preço sombra da capoeira não é somente positivo, mas aumenta no nível de sucessão da capoeira, o que significa que sua função de lucro é côncava. A parte implícita da capoeira no lucro dos estabelecimentos é aproximadamente $22 \%$. O lucro é uma aproximação do valor adicionado do estabelecimento. Assim, a capoeira contribui com mais do que um quarto do valor adicionado do lucro do estabelecimento. Os três fatores que parecem afetar significativamente o preço sombra da capoeira são os preços dos fatores e o nível da terra cultivada. O valor da capoeira aumenta no preço de mercado dos fertilizantes e na área da terra quando diminui a taxa de salário. Por outro lado, um aumento do preço do fertilizante leva os pequenos agricultores a usar menos fertilizantes, o que provoca uma dependência maior da capoeira como fonte de nutrientes. Isso confirma a hipótese de que os fertilizantes e a capoeira são insumos substitutos.

Tabela 7: Elasticidade do lucro em relação às variáveis indicadas ${ }^{\text {a }}$

\begin{tabular}{l|c}
\hline \multicolumn{1}{c|}{ Variáveis } & $\begin{array}{c}\text { Elasticidades } \\
\text { (erros padrão entre parênteses) }\end{array}$ \\
\hline Terra & $0.955(0.122)$ \\
Capoeira & $0.222(0.020)$ \\
Mão-de-obra contratada & $0.140(0.034)$ \\
Fertilizante & $0.099(0.013)$ \\
\hline
\end{tabular}

as médias e os erros-padrão das elasticidades dos estabelecimentos são calculados usando-se uma observação para cada um deles, avaliada com preços médios. Os erros-padrão são calculados com bootstrapping em uma re-amostragem de 500 dados.

O fator que mais afeta o valor da capoeira é a quantidade de terra disponível. A elasticidade da terra é aproximadamente 0.90, o que reflete a complementaridade entre a terra e a capoeira. Além disso, um t-teste de grupos independentes foi realizado. Os resultados mostraram que os agricultores que não usavam fertilizantes têm um preço sombra da capoeira em média $\mathrm{R} \$ 26$ menor do que os agricultores que usavam fertilizante, com a diferença sendo diferente de zero no nível de 10\%. O preço sombra médio dos agricultores que não usavam fertilizantes é $\mathrm{R} \$ 60$ e, para aqueles agricultores que usam fertilizantes, é $\mathrm{R} \$$ 90. Entretanto, a proporção da capoeira no lucro total é maior para aqueles agricultores que não usam fertilizantes (0.34\%) em relação àqueles que usam fertilizantes (0.25\%). Os resultados mostram que os agricultores que usam fertilizantes têm 10\% menos da proporção da capoeira no lucro total do que os agricultores que não usam fertilizantes. Com a análise da variação, pode-se mostrar que as médias são significativamente diferentes no nível de 10\%. 
Dadas as características dos pequenos agricultores da Zona Bragantina, políticas voltadas para uma estrutura de preços sem distorções podem não ser significativamente adequadas para aumentar a produtividade da agricultura familiar. Os preços de produção são claramente importantes na estrutura dos incentivos, mas outros fatores diferentes do preço são também restrições mais importantes. Além dos incentivos nos preços, dar ao pequeno agricultor o acesso à terra, ao crédito e aos insumos é uma política eficaz que contribui para a melhoria da produtividade da agricultura familiar. Tal política pode ter efeitos diretos na produção e aumentar o lucro.

\subsection{Contribuição da tecnologia do mulching para o bem-estar do pequeno agricultor}

A primeira parte da análise foi baseada na teoria da produção. Dois modelos separados foram usados para comparar o lucro obtido nas parcelas, um com e outro sem a tecnologia do mulching (TM). A segunda parte usou um modelo de probit para determinar as características dos agricultores que obtiveram benefício com o TM. Para estimar o lucro obtido com a adoção da tecnologia no estabelecimento, usou-se um modelo econométrico consistente com a maximização de lucro, que segue a mesma aproximação descrita na seção 5.2.

Apesar dos benefícios ambientais potenciais do uso da $\mathrm{TM}^{17}$, os resultados dos modelos do lucro, com e sem TM, mostram que somente uma parte dos agricultores tem vantagem associada ao uso da TM; em geral, os lucros não são afetados significativamente pelo uso da TM. Deve-se lembrar, entretanto, que a análise apresentada neste artigo não considerou os benefícios sociais propiciados pela TM. Além disso, os modelos estimados são baseados em produção agregada, logo não captam os efeitos dos incentivos para substituir dentro da produção agregada. Se esses efeitos adicionais forem analisados e tomados em consideração, o lucro obtido com a TM com certeza tenderá a aumentar.

Ao contrário dos resultados de uma análise financeira baseada nos dados experimentais, que mostraram que, em geral, a TM é melhor do que o sistema de derruba-e-queima (DENICH et al., 2004), as estimativas apresentadas aqui vão mais ao encontro de análises baseadas no nível dos estabelecimentos, que não foram definitivas. Este estudo confirma que a tecnologia terá um impacto positivo nos pequenos agricultores que possuem lotes grandes e família pequena e pertencem a uma organização ou cooperativa. Quando os mercados de crédito são imperfeitos, o tamanho do estabelecimento está correlacionado

\footnotetext{
${ }^{17}$ Segundo Denich et al. (2004), embora não haja um aumento significativo na matéria orgânica do solo quando se adota a tecnología de mulching, ao menos o nível é mantido.
} 
freqüentemente com a liquidez do agricultor, que pode ter capital para investir em TM. Além disso, praticar dois ciclos consecutivos de cultivo é essencial para obter benefício ao usar a TM. Isso reforça a importância das instituições que podem apoiar o uso das tecnologias. Campanhas informativas realizadas pelas cooperativas, divulgadas pela rádio, e exposições, além de assistência técnica, poderão incentivar mais agricultores a praticar dois ciclos de cultivo. Os benefícios dependem não apenas da terra e do trabalho aplicados nessa tecnologia alternativa, mas também do conhecimento do agricultor sobre a execução correta da tecnologia.

Os resultados totais obtidos nos modelos do lucro sugerem que, na ausência de incentivos significativos para os beneficiários globais dos serviços ambientais ou de uma combinação de incentivos dirigidos aos diversos serviços ambientais, os usos racionais no âmbito local levam à subotimização no uso dos recursos, desde a perspectiva global. A proteção da floresta secundária por meio das tecnologías do mulching requererá um esforço a longo prazo. Nesse sentido, a política agroambiental do PROAMBIENTE parece ser sadia, desde que permita que os pequenos agricultores recebam $\mathrm{R} \$ 130$ por mês (metade de um salário mínimo mensal) como remuneração pelos serviços ambientais. Embora o programa tenha sido aceito como uma política pública do governo atual, ainda não foi executado inteiramente. Apesar desses esforços, há necessidade de uma política a longo prazo, baseada na análise científica, para valorizar a produção agrícola, melhorar o bemestar dos pequenos agricultores e, ao mesmo tempo, ajudar a proteger os recursos do solo a fim de manter sua fertilidade e os rendimentos sustentáveis na Amazônia Oriental.

O exemplo da tecnologia do mulching destaca um problema comum no desenvolvimento rural: a adoção de tecnologias é um procedimento-chave para melhorar a produtividade do pequeno agricultor e a renda do estabelecimento, mas a complexidade do processo de adoção traz à tona as dificuldades. Atualmente, um processo de adaptação e de validação da tecnologia do mulching está ocorrendo em Estados selecionados da Amazônia Oriental (KATO, M, informação verbal) com o apoio financeiro do Banco de Amazônia (BASA, 2004). Recomenda-se avaliar esse processo para que os recursos econômicos destinados à promoção da tecnologia sejam usados de forma eficiente. Deve-se dar atenção especial às alternativas de uso do fertilizante nas tecnologias do mulching (isto é, uso de adubos verdes em vez do fertilizante). Criar, promover e adotar práticas sem fogo estão na agenda do desenvolvimento agrícola da região, no entanto mais informações são necessárias. Mais ênfase deve ser dada aos benefícios sociais das tecnologias do mulching, que incluem também o seqüestro do carbono, a melhoria de qualidade da água e a melhora da matéria orgânica do solo. Os resultados deste estudo são por enquanto limitados. Com a 
incorporação futura de externalidades positivas, espera-se aumentar o lucro social dessas tecnologias.

Finalmente, os resultados apresentados aqui são baseados em um modelo de estática que pode ser enganador. Esse modelo ignora os efeitos dinâmicos do processo da adaptação e não tem controles para heterogeneidades não observadas nos estabelecimentos. Conseqüentemente, os resultados devem ser interpretados com cuidado e somente dentro dos limites da análise. O impacto econômico da adoção da tecnologia pode variar em função de diversos fatores, sendo o mais notável o preço. Esses fatores são dinâmicos, e é provável que continuem a mudar ao longo do tempo, junto com a tecnologia e as estruturas do mercado, que terão de evoluir. Não obstante, devido à falta de um painel de dados apropriados, os modelos econômicos estimados e os parâmetros obtidos fornecem informações aos tomadores de decisões a respeito do valor financeiro dos benefícios da tecnologia. Esta análise sugere que, se a tecnologia for dirigida ao grupo apropriado de agricultores, pode melhorar o bem-estar do pequeno agricultor. $\mathrm{O}$ desafio não deve ser simplesmente fornecer incentivos financeiros àqueles que têm potencial para adotar a tecnologia, mas ajudar também os pequenos agricultores mais pobres (com restrição de recursos) de acordo com seus limites de recursos. Isso requereria uma análise das alternativas à tecnologia do mulching. Apesar da discussão crescente sobre programas agroambientais na região, como o PROAMBIENTE, ainda há necessidade de conhecimentos e de análise adicionais.

\subsection{Fatores determinantes do potencial de adoção da tecnologia do mulching}

$\mathrm{Na}$ análise, foram usados métodos de valoração contingente (VC) e um modelo de escolha dupla (double dichotomous choice). Embora um dos objetivos básicos de estudos do VC seja fornecer uma medida sumária da disponibilidade de pagar (WTP), neste estudo não se considerou esse objetivo. O objetivo principal foi identificar os fatores determinantes da adoção das tecnologias do mulching (TM). Deve-se fazer uma observação metodológica: mesmo que o surveyseja projetado para um procedimento de elucidação, usando o modelo de escolha dupla, a falta do significado estatístico das ofertas predeterminadas (bids) mostra que os preços oferecidos aos agricultores que queriam pagar eram baixos em relação aos preços que tiveram de pagar e eram demasiado elevados para aqueles agricultores que não aceitaram as ofertas oferecidas. Para as avaliações futuras, recomenda-se conduzir o survey com um veículo diferente do pagamento, como o trabalho, que parece ser uma restrição importante para adotar as tecnologias do mulching (TM), como foi mostrado com o efeito negativo da relação da 
dependência na probabilidade de pagar as ofertas oferecidas. Isso sugere que é menos provável que os agricultores com famílias maiores paguem as ofertas feitas, um resultado que esta também na linha com os sinais negativos da variável da relação da dependência na regressão.

O segundo estágio do processo de tomada de decisão do agricultor (ou seja, o potencial de adoção) foi analisado, e as variáveis que determinam o potencial de adoção das tecnologias do mulching foram identificadas (FRANZEL et al., 2002; GARCÍA, 2001). O modelo mostrou que fatores institucionais (assistência técnica recebida, experiência com inovações agrícolas e conhecimento de práticas sem fogo), fatores econômicos (renda líquida per capita e uso do fertilizante) e fatores biofísicos (tamanho do estabelecimento e qualidade do solo) foram variáveis importantes para explicar a decisão de adotar ou não potencialmente as tecnologias do mulching.

O tamanho do estabelecimento e a qualidade do solo são aspectos importantes para explicar a disponibilidade dos agricultores em adotar as tecnologias do mulching. Entretanto, a relação entre os dois fatores foi positiva, sugerindo que a promoção das tecnologias deve atingir os locais onde os agricultores não consideram a falta da terra e a qualidade do solo como problemas importantes. Isso significa que, embora a tecnologia do mulching vise a melhoria da qualidade do solo e a intensificação dos ciclos de cultivo, a probabilidade de adotar as tecnologias do mulching aumenta com o tamanho do estabelecimento e com a melhora da qualidade do solo. Há diversos fatores que explicam as razões pelas quais os agricultores de estabelecimentos maiores tendem mais a adotar as tecnologias: a habilidade para distribuir os custos de instalação e/ou de equipamento em um tamanho maior e uma diversificação mais elevada em relação ao risco. O tamanho do estabelecimento é relacionado freqüentemente à riqueza dos agricultores. Os resultados precedentes mostraram também um efeito positivo no benefício do agricultor que usa as tecnologias do mulching. Além disso, os dados do survey sugerem uma correlação positiva entre o tamanho do estabelecimento e a renda do agricultor. De fato, o tamanho médio do estabelecimento do grupo com renda elevada foi aproximadamente duas vezes maior do que o do grupo com a renda mais baixa. Adicionalmente, as famílias com menos rendimentos dependem mais da renda de fora do estabelecimento (30\%) do que as famílias mais ricas (10\%). Esperar-se-ia que os agricultores com dependência maior da renda de fora do estabelecimento tivessem um custo de oportunidade maior com o tempo, e assim seria menos provável que investissem em tecnologias de mulching.

A disposição dos agricultores relativamente mais ricos para adotar as tecnologias do mulching é importante do ponto de vista da mobilização dos recursos, porque esse grupo tem capacidade para pagar 
pelas tecnologias. Além disso, a exclusão do grupo mais pobre pode ser uma questão séria, desde que esse grupo esteja disposto a adotar as tecnologias. Se o meio de pagamento for arranjado sistematicamente de tal maneira que os agricultores possam pagar parte em dinheiro e parte com trabalho, os pequenos agricultores ricos e pobres podem ser atraídos, sem a necessidade de ajustar acima dos níveis dos custos da tecnologia para grupos diferentes de renda. Ainda, deve-se reconhecer que, embora os agricultores mais pobres se beneficiem rara e diretamente com as tecnologias novas, tendem a cultivar lotes menores, ou seja, esses agricultores são mais sujeitos a riscos e menos propensos a interagir com os agentes da extensão (FEDER; JUST; ZILBERMAN, 1985). Eles podem usufruir benefícios líquidos significativos em seu papel de trabalhadores empregados. Se os agricultores com capacidade de pagamento adotarem as tecnologias de mulching em uma extensão suficientemente grande, sem recorrer à mecanização, a demanda de mão-de-obra empregada (e assim os salários) poderá aumentar.

Este estudo mostra que o emprego da tecnologia terá mais impacto nos agricultores que têm lotes maiores, famílias pequenas, acesso à assistência técnica e estão abertos às inovações agrícolas. Não obstante, necessita-se uma análise adicional para identificar os fatores que determinam cada estágio do processo de tomada de decisão do agricultor, visto que o processo potencial de adoção e a própria adoção são dinâmicos. Estudos complementares são necessários também para medir os benefícios externos das tecnologias de mulching fora do estabelecimento, para ajudar a prever subsídios adicionais para incentivar a adoção das tecnologias de mulching na região.

Promover práticas agrícolas sem fogo está na agenda do desenvolvimento agrícola da Amazônia Oriental, mas o conhecimento sobre o impacto econômico dessas tecnologias ainda é insuficiente. Para alimentar o debate que leve à construção de uma ponte entre a geração da tecnologia e a sua adoção, mais avaliações do impacto dos benefícios e dos custos são também necessárias. Quando o modelo apresentado aqui estimou valorações subjetivas dos agricultores sobre as tecnologias de mulching antes de usá-las, a análise forneceu observações úteis sobre a adoção potencial.

\section{CONCLUSÕES E IMPLICAÇÕES PARA POLÍTICAS PÚBLICAS}

Os resultados obtidos pela análise da produção agrícola dos pequenos agricultores têm implicações importantes para o direcionamento das políticas públicas. Primeiramente, os pequenos agricultores tendem a responder aos mecanismos de mercado, mas somente quando existem as tecnologias, instituições e condições biofísicas propícias. Os pequenos agricultores da Zona Bragantina estão 
cada vez mais integrados a um sistema de economia de mercado, e espera-se conseqüentemente que sejam sensíveis às mudanças nos sinais do mercado, como nos preços. A respeito das políticas de preços, este estudo mostrou um grande potencial para a utilização crescente de fertilizante. Esquemas de incentivos ao uso de insumos devem ser mais investigados. Esse resultado pode ajudar a induzir os tomadores de decisões a focalizar a redução dos custos relativamente elevados dos fertilizantes. Reduzi-los levaria a um aumento da área cultivada e do bem-estar, até o ponto de aumentar a renda do estabelecimento. Quanto aos salários rurais, os resultados sugerem que os salários rurais mais elevados provocam somente um pequeno aumento na produtividade agrícola. Conseqüentemente, existem razões fortes para acreditar que as políticas que favorecem os aumentos de salários rurais e geram oportunidades de emprego externas ao estabelecimento devem reduzir a pressão sobre os recursos naturais.

A importância quantitativa da capoeira na produção da Zona Bragantina sugere que a capoeira é um fator determinante importante da renda do agricultor. Embora não se tenha chegado a nenhuma conclusão definitiva sobre a relação da capoeira com a produtividade a longo prazo, seu papel a curto prazo parece ser importante. Uma alternativa para o governo deveria ser elaborar regimes de conservação, que incentivem diretamente os agricultores a usar mais eficientemente a capoeira. Tais políticas reforçariam os incentivos econômicos para o manejo dos recursos.

Em relação às práticas agrícolas sem fogo, observou-se que cresce a importância dos pequenos agricultores na região da Bragantina e dos impactos ambientais negativos das práticas de derruba-e-queima. Os esforços realizados na região para reduzir as práticas do uso de fogo consistiram em incentivar as práticas sem fogo, que podem também compensar as perdas do rendimento devido à degradação do solo. Infelizmente, a experiência na área mostra um sucesso limitado na apropriação da tecnologia pelos agricultores. Uma razão é que os agricultores reconheceram que plantar é difícil, assim como remover as ervas daninhas (devido à camada do mulch), e os rendimentos são mais baixos no primeiro ciclo do cultivo. Essa última razão pode estar ligada às práticas impróprias de fertilização.

Este estudo confirma que a tecnologia terá um impacto positivo nos pequenos agricultores que têm estabelecimentos maiores e família pequena e naqueles que pertencem a uma organização de agricultores. Além disso, praticar dois ciclos consecutivos de cultivo é fundamental para ter uma diferença positiva ao usar a tecnologia de mulching. Isso reforça a importância das instituições que podem valorizar o uso da tecnologia. Para exemplificar, as campanhas de assistência técnica e de 
informação por intermédio das cooperativas, a união de agricultores, a rádio, exposições com demonstrações etc. poderão incentivar mais agricultores a praticar dois ciclos de cultivo. Os resultados empíricos da análise potencial da adoção poderiam ser úteis para desenvolver e implantar estratégias para a promoção e a difusão da tecnologia de mulching. Particularmente, devem ser feitas alterações nas formulações das políticas no que diz respeito ao alvo pretendido.

Para resumir, quatro lições podem ser extraídas deste estudo sobre as implicações políticas. Primeiramente, os esforços do governo visando a melhoria do bem-estar econômico dos pequenos agricultores devem focalizar mais tecnologias como o uso do fertilizante, para assim poder atingir um número maior de estabelecimentos. As intervenções das políticas que se concentram na fixação de preços no mercado melhorarão as rendas rurais. Em segundo lugar, as políticas que favorecem o aumento dos salário rurais e geram oportunidades de emprego fora do estabelecimento devem reduzir a pressão sobre os recursos naturais. Em terceiro lugar, o governo não deve negligenciar a importância da capoeira para a produção dos pequenos agricultores e os benefícios que provêm dos sistemas de pousio, já que a capoeira representa um fator importante da produção, que poderia aumentar o bem-estar dos pequenos agricultores. Em quarto lugar, dirigir as tecnologias de mulching para o grupo apropriado de pequenos agricultores terá um impacto positivo no bem-estar deles. Por isso, repete-se, devem ser feitas alterações nas formulações da política no que diz respeito ao alvo pretendido. Finalmente, cabe ressaltar que a discussão sobre os impactos prováveis da tecnologia de mulching no bem-estar dos pequenos agricultores é limitada. As tecnologias de mulching têm de competir com outras tecnologias menos custosas, como derruba-e-queima, fertilização e mecanização convencional. Dessa forma, desde que os custos externos associados a essas tecnologias não derrubar os custos de promover a tecnologia de mulching, a intervenção direta do governo não é a melhor solução.

\section{AGRADECIMENTOS}

Este artigo contou com o apoio do Ministério Federal Alemão da Educação, Ciência, Pesquisa e Tecnologia (BMBF), que financiou esta pesquisa no âmbito do projeto Studies for Human Impact on Forests and Floodplains in the Tropics (SHIFT ENV 44). A autora agrade o apoio institucional do Centro de Pesquisa para o Desenvolvimento (ZEF), Universidade de Bonn, Alemanha, da EMBRAPA-Amazônia Oriental, Pará, Brasil, e do Núcleo de Altos Estudos Amazônicos (NAEA) da Universidade Federal do Pará (UFPA), Brasil. Pelo apoio na revisão e na correção do português, a autora agradece a Claudia Kahwage. 


\section{REFERÊNCIAS}

ABRAR, S.; MORRISEY, O.; RAYNER, T. Supply Response of Peasant Farmers in Ethiopia: a Farm-Level Profit Function Analysis. Centre for Research in Economics Development and International Trade, University of Nottingham. CREDIT Research Paper, n. 16, p. 01-49, 2002.

AHAMMAD, H.; ISLAM, N. Estimating Agricultural Production Systems of Western Australia: a Profit Function Approach. Crawley, Austrália: University of Western Australia, 1999 (Working Paper, 11).

AlBurquerque, M.; CARDOSO, E. M. R.. A mandioca no Trópico Úmido. Brasília, DF: Editerra, p. 251. 1980.

ALMEIDA, O.; UHL; C. Developing a Quantitative Framework for Sustainable Resource-use Planning in the Brazilian Amazon. World Development, New York: Columbia University Press, n. 23, p. 17451753, 1995.

ANGELSEN, A.; KAIMOWITZ, D. Rethinking the Causes of Deforestation: Lessons from Economic Models. The World Bank Researcher Observer, Oxford University Press, Oxford, n. 14, p. 73-98, 1999.

ARIMA, E.; UHL, C. Ranching in the Brazilian Amazon in a National Context: Economics, Policy and Practice. Society and Natural Resources. Mimo. IMAZON. Belém., n. 10, p. 433-451, 1997.

AUNE, J. B.; GLOMSROD, S.; IVERSEN, V.; WIIG, H. Structural Adjustment and Soil Degradation in Tanzania: a CGE-Model Approach with Endogenous Soil Productivity. Oslo: Research Department, 1997 (Discussion Paper, 189).

BAAR, R.; CORDEIRO, M. dos Reis; DENICH, M.; FÖLSTER, H. Floristic Inventory of Secondary Vegetation in Agricultural Systems of EastAmazonia. Biodiversity and Conservation, Springer Netherlands, n. 13, p. 501-528, 2004.

BAPNA, S. L.; BINSWANGER, H. P.; QUIZON, J. B. Systems of Output Supply and Factor Demand Equations for Semi-Arid Tropical India. Indian Journal of Agricultural Economics, n. 39, p. 179-202, 1984.

BAUTISTA, R. M. Domestic Price Distortions and Agricultural Income in Developing Countries. Journal of Development Economics, n. 23, p. 19-39, 1986.

BEYERS, L.; HASSAN, R. The Structure of South African Milk Production Technology: a Parametric Approach to Supply Analysis. Department of 
Agricultural Economics, Extension and Rural Development, University of Pretoria, South Africa, 2000 (Working Paper, 4). Disponível em: < http:/ /www.up.ac.za/academic/ecoagric/fulltext/2000-04.pdf>._Acesso em: 20 ago. 2003.

BÖRNER, J.; MENDOZA-ESCALANTE, A.; HEDDEN-DUNKHORST, B.; HURTIENNE, T. Sampling Frame: Selection of Survey Sites and Sampling Design of the Project SHIFT, ENV-44. Center for Development Research, University of Bonn, 2002. Internal Paper.

BRASIL. Ministério do Desenvolvimento Agrário. Novo retrato da agricultura familiar: o Brasil redescoberto. Brasilia: INCRA/FAO, p. 74, 2000.

BRASIL. Ministério do Meio Ambiente. Plano Plurianual 2004-2007. Disponível em: <http://www.mma.gov.br/>. Acesso em: 12 out. 2003.

BURGER, D. Land use in the Eastern Amazon Region. In: EMBRAPACPTU-GTZ. Studies on the Utilization and Conservation of Soil in the Eastern Amazon Region. Final Report of the Agreement between EMBRAPA-CPTU-GTZ. Eschborn, Germany: Deutsche Gesellschaft für Technische Zusammenarbeit (GTZ), p. 69-93, 1991.

CORLETT, R. T. Tropical Secondary Forests. Progress in Physical Geography, n. 19, p. 159-172, 1995.

CORREA, V.; ORTEGA, A. C. Pronaf - Programa Nacional de fortalecimento da agricultura familiar: qual o seu real objetivo e públicoalvo. 2003. Paper apresentado no XL Congresso da Sociedade Brasileira de Economia e Sociologia Rural, Passo Fundo-RS, 2003.

COSTA, F. de A. Ecologismo e questão agrária na Amazônia. Belém: NAEA-UFPA, 1992.

COSTA, F. de A. Políticas públicas e dinâmica agrária na Amazônia: dos incentivos fiscais ao FNO. In: TURA, L. R.; COSTA, F. (Ed.), Campesinato e Estado na Amazônia: impactos do FNO no Pará. Brasília: Brasília Jurídica-FASE, p. 1-381, 2000.

DENICH, M. Untersuchungen zur Bedeutung junger Sekundärvegetation für die Nutzungssystemproduktivität im östlichen Amazonasgebiet, Brasilien. Göttinger Beiträge zur Land- und Forstwirtschaft in den Tropen und Subtropen, Göttingen, Germany, n. 46, p. 246-265, 1989.

DENICH, M. Vegetation in the Eastern Amazon Region. In: EMBRAPACPTU-GTZ. Studies on the Utilization and Conservation of Soil in the 
Eastern Amazon Region. Final Report of the Agreement between EMBRAPA-CPTU-GTZ. Eschborn, Germany: Deutsche Gesellschaft für Technische Zusammenarbeit (GTZ), p. 43-68. 1991.

DENICH, M. Small Farming in the Humid Tropics: a Case Study from the Brazilian Amazon. 2001. Lecture presented for the International Doctoral Program at the Center for Development Research (ZEF), University of Bonn, Germany, 2001.

DENICH, M.; VIELHAHUER, K.; KATO, M. S. de A.; BLOCK, A.; KATO, O. R.; SÁ, T. D. de Abreu; LÜCKE, W.; VLECK, P. L. G. Mechanized Land Preparation in Forest-based Fallow Systems: the Experience from Eastern Amazonia. Agroforestry Systems, n. 61, p. 91-106, 2004.

FALESI, I. C.; BAENA, A. R. C.; DUTRA, S. Levantamento de Recocimento dos Solos da Regiao Bragantina, Estado do Lora. Pesquisa Agropecuária Brasileira, n. 2, p. 1-63, 1967.

FALESI, I. C.; BAENA, A. R. C.; DUTRA, S. Conseqüências da exploração agropecuária sobre as condições físicas e químicas dos solos das microrregiões do Nordeste paraense. Belém: EMBRAPA - Centro de Pesquisa Agropecuária do Trópico Úmido, 1980. Boletim de Pesquisa, 14.

FEARNSIDE, P. Quem está desmatando a Amazônia: os ricos ou os pobres? Manaus, 1994. Mimeografado.

FEDER, G.; JUST, R. E.; ZILBERMAN, D. Adoption of Agricultural Innovations in Developing Countries: a Survey. Economic Development and Cultural Change, n. 33, p. 255-298, 1985.

FLOHRSCHUETZ, G. H. H.; KITAMURA, P. Small-scale Agriculture in the Eastern Amazon Region. In: EMBRAPA-CPTU-GTZ. Studies on the Utilization and Conservation of Soil in the Eastern Amazon Region. Final Report of the Agreement between EMBRAPA-CPTU-GTZ. Eschborn, Germany: Deutsche Gesellschaft für Technische Zusammenarbeit (GTZ), 1991. p. 95-112.

FONTEIN, P. F.; THIJSSEN, G. J.; MAGNUS, J. R.; DIJK, J. On Levies to Reduce the Nitrogen Surplus: the Case of Dutch Pig Farms. Environmental and Resource Economics, n. 4, p. 455-478, 1994.

FRANZEL, S.; SCHERR, S. J.; COE, R.; COOPER, P. J. M.; PLACE, F. Methods for Assessing Agroforestry Adoption Potential. In: FRANZEL, S.; SCHERR, S. J. (Ed.). Tree on the Farm: Assessing the Adoption 
Potential of Agroforestry Practices in Africa. Local: CABI Publishing, p. $11-35,2002$.

GARCIA, Y. T. Analysis of Farmer Decisions to Adopt Soil Conservation Technology in Argao. In: CRAMB R. A. (Ed.). Soil Conservation Technologies for Smallholder Farming Systems in the Philippine Uplands: a Socioeconomic Evaluation. Canberra, Australia: ACIAR, p, 1-19, 2001.

HEDDEN-DUNKHORST, B.; DENICH, M.; MENDOZA-ESCALANTE, A.; BÖRNER, J.; HURTIENNE, T.; SOUSA FILHO, F. R. de; SÁ, T. D. de A.; COSTA, F. de A. Forest-based Fallow Systems: a Safety Net for Smallholders in the Eastern Amazon? 2003. Paper apresentado na International Conference on Rural Livelihoods, Forests and Biodiversity, Bonn, Germany, maio 2003.

HELFAND, S. The Impact of Agricultural Policy Reforms on the Agricultural Sector in Brazil in the 1990s: Implications for Pro-Poor Agricultural Policies. 2003. Paper apresentado para discussão no OECD Forum on Agriculture: Designing and Implementing Pro-Poor Agricultural Policies, dez. 2003.

HOLDEN, S. T. Adjustment Policies, Peasant Household Resource Allocation, and Deforestation in Northern Zambia: an Overview and Some Policy Conclusions. Forum for Development Studies, n. 1, p. 117134, 1997.

HÖLSCHER, D.; LUDWIG, B.; MÖLLER, M. R. F.; FÖLSTER, H. Dynamic of Soil Chemical Parameters in Shifting Agriculture in the Eastern Amazon Region. Agriculture Ecosystems and Environment, n. 66, p. 153-163, 1997.

HOTELLING, H. Edgeworth's Taxation Paradox and the Nature of Demand and Supply Functions. Journal of Political Economy, n. 40, p. 577-616, 1932.

HUBBELL, B. J.; MARRA, M. C.; CARLSON, G. A. Estimating the Demand for a New Technology: Bt Cotton and Insecticide Policies. American Journal of Agricultural Economics, n. 82, p. 118-132, 2000.

HUFFMAN, W. E.; EVENSON, R. E. Supply and Demand Functions for Multi-product U.S. Cash Grain Farms: Biases Caused by Research and Other Policies. American Journal of Agricultural Economics, n. 71, p. 761-773, 1989. 
HURTIENNE, T. Agricultura familiar e desenvolvimento rural sustentável na Amazônia. In: COELHO, M. C.; CASTRO, E.; HURTIENNE, T.; MATHIS, A. (Org.). Estado e políticas úblicas na Amazônia: gestão do desenvolvimento. Belém: Cegup, p. 21-71. 2002.

IBGE. Censo Agropecuário 1995-1996. Rio de Janeiro, 1998.

KATO, M. S. A. Fire-free Land Preparation as an Alternative to Slashand-burn Agriculture in the Bragantina Region, Eastern Amazon: Crop Performance and Phosphorous Dynamics. 1998. ... f. Tese (Doctor of Agricultural Science) - Faculty of Agricultural Science, George-AugustUniversity of Göttingen, Germany, 1998.

KATO, O. R. Fire-free Land Preparation as an Alternative to Slash-andburn Agriculture in the Bragantina Region, Eastern Amazon: Crop Performance and Nitrogen Dynamics. ... f. Tese (Doctor of Agricultural Science) - Faculty of Agricultural Science, George-August-University of Göttingen, Germany, 1998.

KHERALLAH, M.; GOVIDAN, K. The Sequencing of Agricultural Market Reforms in Malawi. Journal of African Economies, Washington, n. 8, p. 125-151, 1999.

KITAMURA, P. Agricultura migratória na Amazônia: um sistema de produção viável. Belém: EMBRAPA-CPTU, 1982. Documento 12.

LAU, L. J. A Characterization of the Normalized Restricted Profit Function. Journal of Economic Theory, n. 12, p. 131-163, 1976.

LAU, L. J. Application of Profit Functions. In: FUSS, M.; MacFADDEN, D. (Ed.) Production Economics: a Dual Approach to Theory and Applications. Amsterdam: North-Holland, p. 133-216. 1978.

LÓPEZ, R. Trade Reform and Environmental Externalities in General Equilibrium: Analysis for an Archetype Poor Tropical Country. Environmental and Development Economics, n. 5, p. 377-404, 2000.

LUDEWIGS, T. Agricultural Credit and the Build-up of Social Capital in the Brazilian Amazon Frontier. 2002. Paper apresentado na MiniConference on Institutional Analysis and Development, dez. 2002.

MENDOZA-ESCALANTE, A. Analysis of Smallholder Agricultural Production in the Eastern Amazon: Empirical Evidence and Policy Perspectives for the Bragantina Region. Göttingen, Germany: Cuviller Verlag, p. 222, 2005. 
MONELA, G. C. Tropical Rainforest Deforestation, Biodiversity Benefits, and Sustainable Land Use: Analysis of Economic and Ecological Aspects Related to the Nguru Mountains. 1996. ... f. Tese (PhD) -Department of Forest Sciences, University of Norway, Norway, 1996.

QAIM, M.; JANVRY, A. de. Genetically Modified Crops, Corporate Pricing Strategies, and Farmer's Adoption: the Case of Bt Cotton in Argentina. Journal of Agricultural Economics, Local, n. 85, p. 814-828, 2003.

ROCHA, V. Environmental and Structural Constraints for Rural Development Programs in the Brazilian Amazon. 1993 ... f. Tese (Doctor of Philosophy) - Boston University Graduate School, Boston, 1993.

SAMUELSON, P. A. Prices of Factors and Goods in General Equilibrium. Review of Economic Studies, n. 21, p. 1-20, 1953.

SCATENA, F. N.; WALKER, R. T.; HOMMA, A. K. O.; CONTO, A. J. de; FERREIRA, C. A. P.; CARVAlHO, R. de A.; ROCHA, A. C. P. N. da; SANTOS, A. I. M. dos; OLIVEIRA, P. M. de. Cropping and Fallowing Sequences of Small Farms in the "terra firme" Landscape of the Brazilian Amazon: a Case Study from Santarem, Para. Ecological Economics, n. 18, p. 29-40, 1996.

SERRÃO, E. A. S.; HOMMA, A. Brazil Country Profile. In: NATIONAL RESEARCH COUNCIL (Org.). Sustainable Agriculture and the Environment in the Humid Tropics. Washington D.C.: National Academy Press, p. 265-351, 1993.

SHEPARD, R. W. Theory of Cost and Production Functions. Princenton: Princenton University Press, 1970.

SHUMWAY, C. R. Supply, Demand, and Technology in a Multiproduct Industry: Texas Field Crops. American Journal of Agricultural Economics, n. 65, p. 748-760, 1983.

SHUMWAY, C. R.; ALEXANDER, W. P. Agricultural Product Supplies and Input Demands: Regional Comparisons. American Journal of Agricultural Economics, n. 70, p. 153-161, 1988.

SMITH, N.; FALESI, I. C.; ALVIM, P. de T.; SERRÃO, E. A. S. Agroforestry Trajectories among Smallholders in the Brazilian Amazon: Innovation and Resiliency in Pionner and Older Settled Areas. Ecological Economics, n. 18, p. 15-27, 1996. 
SMITH, N.; SERRÃO, E. A. S.; ALVIM, P. de T.; FALESI, I. C. Amazonia: Resiliency and Dynamism of the Land and its People. Tokyo: United Nations University Press, 1995.

SOMMER, R. Water and Nutrient Balance in Deep Soils under Shifting Cultivation with and without Burning in the Eastern Amazon. 2000. ... f. Tese (Doctor of Agricultural Science) - Faculty of Agricultural Science, George-August-University of Göttingen, Germany, 2000.

SOMMER, R.; DENICH, M.; VLECK, P. L. G. Carbon Storage and Root Penetration in Deep Soils under Small-farmer Land-use in the Eastern Amazon Region, Brazil. Plant and Soil, n. 219, p. 231-241, 2000.

TONIOLO, A.; UHL, C. Economic and Ecological Perspectives on Agriculture in the Eastern Amazon. World Development, n. 23, p. 959973, 1995.

TURA, L. R. Notas introdutórias sobre os fundos constitucionais de financiamento e sua configuração na Região Norte. In: TURA, L.R.; COSTA, F. (Ed.), Campesinato e Estado na Amazônia: impactos do FNO no Pará. Brasília. Brasília Jurídica-FASE, p. 29-46, 2000.

VERNER, D. Poverty in the Brazilian Amazon: an Assessment of Poverty Focused on the State of Pará. World Bank Policy Research Working Paper, Washington, DC (USA), n. 3357, p. 1-66, 2004.

VIELHAUER, K.; SÁ T.D. de A.; KANASHIRO, M.; DENICH, M. Technology development of slash-and-mulch and of fallow enrichment in shifting cultivation systems of the Eastern Amazon. In: SHIFT-WORKSHOP, 3., 1998, Manaus. Proceedings. [S.I.: s.n.], p.49-59, 1998.

VOSTI, S. A.; WITCOVER, J.; CARPENTIER, CH. L. Agricultural Intensification by Smallholders in the Western Brazilian Amazon: from Deforestation to Sustainable Land Use. International Food Policy Research Institute (IFPRI), 2002. Research Report, 130.

WALL, C. A.; FISHER, B. S. Modelling a multiple output production system: supply response in the Australian sheep industry. Sydney: University of Sydney Printing Service, 1987.

XIMENES, T. Division of Labor and Resource Management in Eastern Pará, Brazil. Agriculture and Human Values, Belém-PA, n. 18, p. 4956, 2001. 